\title{
Effects of the total replacement of fish-based diet with plant-based diet on the hepatic transcriptome of two European sea bass (Dicentrarchus labrax) half-sibfamilies showing different growth rates with the plant-based diet
}

Florian Geay ${ }^{1}$, Serena Ferraresso ${ }^{2}$, Jose L Zambonino-Infante ${ }^{1}$, Luca Bargelloni², Claire Quentel ${ }^{3}$, Marc Vandeputte ${ }^{4,5}$, Sachi Kaushik ${ }^{6}$, Chantal L Cahu ${ }^{1}$ and David Mazurais ${ }^{1 *}$

\begin{abstract}
Background: Efforts towards utilisation of diets without fish meal (FM) or fish oil (FO) in finfish aquaculture have been being made for more than two decades. Metabolic responses to substitution of fishery products have been shown to impact growth performance and immune system of fish as well as their subsequent nutritional value, particularly in marine fish species, which exhibit low capacity for biosynthesis of long-chain poly-unsaturated fatty acids (LC-PUFA). The main objective of the present study was to analyse the effects of a plant-based diet on the hepatic transcriptome of European sea bass (Dicentrarchus labrax).

Results: We report the first results obtained using a transcriptomic approach on the liver of two half-sibfamilies of the European sea bass that exhibit similar growth rates when fed a fish-based diet (FD), but significantly different growth rates when fed an all-plant diet (VD). Overall gene expression was analysed using oligo DNA microarrays (GPL9663). Statistical analysis identified 582 unique annotated genes differentially expressed between groups of fish fed the two diets, 199 genes regulated by genetic factors, and 72 genes that exhibited diet-family interactions. The expression of several genes involved in the LC-PUFA and cholesterol biosynthetic pathways was found to be upregulated in fish fed VD, suggesting a stimulation of the lipogenic pathways. No significant diet-family interaction for the regulation of LC-PUFA biosynthesis pathways could be detected by microarray analysis. This result was in agreement with LC-PUFA profiles, which were found to be similar in the flesh of the two half-sibfamilies. In addition, the combination of our transcriptomic data with an analysis of plasmatic immune parameters revealed a stimulation of complement activity associated with an immunodeficiency in the fish fed VD, and different inflammatory status between the two half-sibfamilies. Biological processes related to protein catabolism, amino acid transaminations, RNA splicing and blood coagulation were also found to be regulated by diet, while the expression of genes involved in protein and ATP synthesis differed between the half-sibfamilies.
\end{abstract}

Conclusions: Overall, the combined gene expression, compositional and biochemical studies demonstrated a large panel of metabolic and physiological effects induced by total substitution of both FM and FO in the diets of European sea bass and revealed physiological characteristics associated with the two half-sibfamilies.

\footnotetext{
* Correspondence: David.Mazurais@ifremer.fr

'Ifremer, UMR 1067, Departement Physiologie Fonctionnelle des Organismes

Marins, Technopôle Brest-lroise, BP 70, 29280 Plouzané, France

Full list of author information is available at the end of the article
} 


\section{Background}

For the majority of intensively-reared finfish species including the European sea bass (Dicentrarchus labrax), diets have traditionally been based on fish meal (FM) and fish oil (FO). However, the decline in worldwide supplies of marine oils and fish meal [1] has led the industry and several research initiatives to investigate the possibility of using plant proteins and vegetable oils as alternatives to marine fishery-derived proteins and oils. Nevertheless, the use of such plant products is recognised to have several disadvantages, particularly related to their protein contents, amino acid profiles and unsaturated fatty acid imbalances, but also including endogenous anti-nutritional factors. Taking into account these limits and the dietary needs of different fish species, efforts have been made over the last decade to develop diets with a low content in fish resources. This has been done by using a mixture of vegetable meals and oils [2], resulting in the successful reduction of both FM and FO in the feeds for several species [3]. Much progress has indeed been made in the substitution of FM and FO with plant products in feeds for salmonids as well as marine fish, in the recent past [4-6]. While several studies performed on salmonids indicate that total replacement of fish meal by plant ingredients leads to decreased growth rate [7,8], Kaushik et al. [9] showed that it was possible to almost totally replace fish meal with a mixture of plant protein sources for European sea bass without reducing growth performance. The same authors did, however, note a significant increase in fat content and a decrease in plasma cholesterol concentrations for sea bass fed with plant protein, suggesting altered regulation of lipid metabolic pathways.

For the replacement of fish oil, it is well established that freshwater or anadromous fish species such as salmonids have higher tolerance to vegetable oil compared with marine fish species. Thus, for Atlantic salmon (Salmo salar) and rainbow trout (Oncorhynchus mykiss), the total replacement of fish oil with a blend of vegetable oils poor in highly unsaturated fatty acids (LCPUFA) did not result in diminished growth performance, feed conversion or development of histopathology, despite an increase of polyunsaturated fatty acid (PUFA) deposition in liver and muscle [10-12]. In some studies, a high or total substitution of fish oil by linseed and soybean oils for several months induced decreases in growth rate of gilthead sea bream (Sparus aurata) and European sea bass (Dicentrarchus labrax) [13-15]. Some other studies undertaken with gilthead sea bream showed that while there were no differences in growth of fish fed high levels of vegetable oil mixtures, there were possibly other metabolic consequences $[5,16]$. This lower adaptation of marine fish species to vegetable oil has been suggested to be linked to their lower efficiency at synthesizing LC-PUFA from n-3 and n-6 precursors present in plants [17-19]. A recent study performed on European sea bass indicates that the limiting step for LC-PUFA synthesis could be linked to a deficiency in the stimulation of delta-6-desaturase (FADS2) activity in fish fed vegetable oil [13]. The resulting low tissue levels of LC-PUFA in marine fish fed vegetable oil could impact fish health, since LC-PUFA are not only important as structural components of cell membranes but also as precursors of eicosanoids. Eicosanoids are involved in many physiological processes, including osmoregulation, immune responses, blood coagulation and reproduction [20-23]. Moreover, lowered eicosapentaenoic acid (EPA; 20:5n-3) and docosahexaenoic acid (DHA; 22:6n-3) content in the flesh of marine fish fed a vegetable diet diminishes their nutritional value for consumers.

Recent studies on salmonids have suggested there is genetic variability for ability to utilize plant-based diets [24-26]. Interestingly, some genotype-diet interactions for growth have also been recently demonstrated in European sea bass fed on a plant-based diet [27]. The existence of such interactions suggests that it could be possible to select fish, and particularly sea bass, with a better ability to grow on plant-based feeds. However, the genetic factors and related metabolic or physiological pathways responsible for these advantageous capacities are still unknown.

To our knowledge, studies on the total replacement of both FM and FO have not been undertaken in a marine fish species until now, except for the afore mentioned work by Le Boucher et al. (2010) [27]. Moreover, investigations on the impact of FM and FO substitution with plant products for marine fish species have only been performed using molecular and/or biochemical approaches focused on selected target metabolic pathways or physiological functions. Such dedicated approaches do not allow an exhaustive and global overview of the molecular mechanisms underlying tissue and organism response to diet substitution.

In order to gain a fuller picture of the effects of total substitution of both FM and FO, the present study primarily aimed to characterise the regulation of the liver transcriptome in European sea bass fed on a fish-free diet for 9 months, using an oligonucleotide microarray recently developed for this species [28]. This investigation was performed on liver because this organ plays a key role in intermediary metabolism, integrates a large part of nutrient uptake and affects a wide range of functions in the body, including plasma protein synthesis, hormone production and detoxification. The present study was undertaken using two half-sibfamilies that exhibited similar growth rates when they were fed a FM-FO diet, but different growth rates when they were 
fed a plant protein-vegetable oil based diet. The second aim of this work was to pinpoint genes and related metabolic and physiological pathways that could explain the different adaptation of these two half-sibfamilies of European sea bass to a plant-based diet. The hepatic transcriptomes and flesh LC-PUFA profiles were, therefore, compared between these half-sibfamilies.

\section{Methods}

\section{Diets and fish}

Two practical iso-energetic and iso-nitrogenous diets were formulated (Table 1). The first, a fish-based diet (FD), was composed of fish meal, wheat gluten and fish oil whereas the second, a vegetable-based diet (VD), was devoid of ingredients of fish origin and composed of plant protein sources and vegetable oil (linseed). The fatty acid composition of the two diets is given in Table 2 .

All procedures concerning the animals and their handling were conducted in accordance with the Code of Ethics of the World Medical Association (Declaration of Helsinki). The study was performed under licence no. 29.021 of the French Department of Veterinary Services (Direction Départementale des Services Vétérinaires) to conduct experimental protocols and samplings on fish. The present study focused on fish of two half-sibfamilies (half-sibfamily $G$ and half-sibfamily $g$ ), which exhibited a similar daily growth coefficient (DGC) when they were fed on a fish-based diet, but had significantly different DGCs when they were fed an all-plant diet. The two half-sibfamilies of fish were produced from a crossing design between 8 females and 41 males, which was carried out with European sea bass individuals from a Mediterranean stock held at the Experimental Station of Palavas-les-Flots (Ifremer, France) [27]. Rearing conditions have already been described by Le Boucher et $a l$. [27]: fish were reared in two tanks per diet condition, supplied with recirculated seawater (38 ppt) at a constant temperature of $21^{\circ} \mathrm{C}$, and subjected to a photoperiod of $12 \mathrm{~h}$ light: $12 \mathrm{~h}$ dark. Fish were fed on a commercial diet (Neogrower, Le Gouessant, Lamballe, France) until they reached the mean weight of $192 \mathrm{~g}$. Before the beginning of the nutritional challenge, fish were individually tagged, genotyped for microsatellite markers to infer parentage [27], and distributed randomly into two tanks per dietary condition (FD or VD), with 196 fish per tank. After an acclimation period of 2 weeks, fish were hand fed to satiation (1 meal/day) for a period of 9 months on the experimental diets (FD or VD). Analysis of experimental data was done using the following formulae:

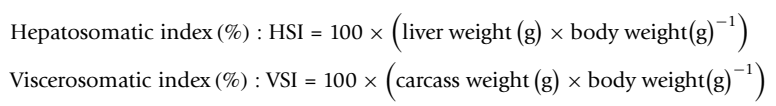

Table 1 Ingredients, amino acid profiles and chemical composition of the two diets fed to European sea bass.

\begin{tabular}{|c|c|c|}
\hline Diets & FD & VD \\
\hline \multicolumn{3}{|l|}{ Ingredients } \\
\hline Fish meal & 38.0 & 0.0 \\
\hline Corn gluten & 18.0 & 20.0 \\
\hline Soybean meal & 0.0 & 18.2 \\
\hline Wheat gluten & 7.2 & 20.0 \\
\hline Whole wheat & 25.3 & 7.2 \\
\hline White sweet lupin & 0.0 & 14.0 \\
\hline Fish oil & 8.5 & 0.0 \\
\hline Linseed oil & 0.0 & 9.4 \\
\hline Soy lecithin & 0.0 & 1.0 \\
\hline L-lysine & 0.0 & 2.7 \\
\hline Dicalcium phosphate & 0.0 & 3.0 \\
\hline Binder (Sodium alginate) & 1.0 & 1.0 \\
\hline Attractant mix & 1.0 & 1.5 \\
\hline Mineral premix ${ }^{2}$ & 1.0 & 1.0 \\
\hline Vitamin premix $x^{3}$ & 1.0 & 1.0 \\
\hline
\end{tabular}

\begin{tabular}{lcc} 
Chemical composition & & \\
\hline Dry matter (DM), g/100 g & 94.5 & 90.3 \\
Crude protein, g/100 g DM & 49.8 & 50.3 \\
Crude fat, g/100 g DM & 14.3 & 14.1 \\
Gross energy (GE), kJ/g DM & 22.8 & 21.9 \\
Ash, g/100 g DM & 6.3 & 7.9
\end{tabular}

Amino acid composition ( $\mathrm{g} / 100 \mathrm{~g})$

\begin{tabular}{lcc}
\hline Arginine & 2.2 & 1.8 \\
Histidine & 1.0 & 0.9 \\
Isoleucine & 1.9 & 1.8 \\
Leucine & 4.2 & 3.9 \\
Lysine & 2.5 & 3.6 \\
Methionine+Cystine & 1.8 & 1.4 \\
Phenylalanine+Tyrosine & 3.8 & 3.7 \\
Threonine & 1.7 & 1.3 \\
Tryptophan & 0.4 & 0.3 \\
Valine & 2.3 & 1.9 \\
Glycine & 2.5 & 3.5 \\
Serine & 2.2 & 4.7 \\
Glutamic acid & 10.6 & 22.1 \\
Aspartic acid & 3.3 & 7.6 \\
Proline & 2.8 & 5.4 \\
Alanine & 2.8 & 3.0 \\
\hline
\end{tabular}

Ingredient composition (g $\left.100 \mathrm{~g}^{-1}\right)$, amino acid profiles $\left(\mathrm{g} 100 \mathrm{~g}^{-1}\right)$ and chemical composition $\left(\mathrm{g} / 100 \mathrm{~g} \mathrm{DM}^{-1}\right)$ of the two diets fed to European sea bass.

${ }^{1}$ Attractant mix contained: glycine $(0.2)$, alanine $(0.2)$, betaine $(0.3)$, taurine (0.3) and glucosamine (0.5)

23 as per NRC [75]

Daily growth coefficient (\% day): DGC $=100 \times($ final individual weight $(\mathrm{g})^{1 / 3}$ - initial individual weight $\left.(\mathrm{g})^{1 / 3}\right) /$ days (According to Cho [29]). 
Table 2 Fatty acid composition (\% sum of fatty acids) of the two diets FD and VD

\begin{tabular}{lcc}
\hline Diets & FD & VD \\
\hline Fatty acids composition & & \\
\hline$\Sigma$ saturates & 27.67 & 11.82 \\
$\Sigma$ monoenes & 36.27 & 23.85 \\
18:2n-6 & 8.90 & 23.59 \\
20:2n-6 & 0.25 & 0.11 \\
18:3n-6 & 0.22 & 0.10 \\
20:4n-6 & 0.71 & 0.00 \\
$\Sigma$ n-6 PUFA & 10.31 & 23.91 \\
18:3n-3 & 1.27 & 40.90 \\
18:4n-3 & 1.84 & 0.00 \\
20:3n-3 & 0.13 & 0.07 \\
20:4n-3 & 0.87 & 0.00 \\
20:5n-3 & 9.54 & 0.05 \\
22:5n-3 & 1.56 & 0.00 \\
22:6n-3 & 10.52 & 0.12 \\
$\Sigma$ n-3 PUFA & 25.73 & 41.14 \\
total lipid (\%) & 13.80 & 13.10 \\
\hline$\Sigma$ n-3 PUFA/ $\Sigma$ n-6 PUFA & 2.5 & 1.7 \\
EPA/DHA & 0.9 & 1.0 \\
EPA/ARA & 13.6 & - \\
\hline
\end{tabular}

Feed efficiency (FE): [final weight (g) - initial weight (g)]/feed ration (g) (According to Carter et al. [30])

At the end of the growth trial, liver, muscle and plasma were sampled from 15 fishes per half-sibfamily and per dietary treatment. Muscular LC-PUFA profiles and real-time PCR investigations were performed on these 15 sampled individuals per group. Microarray analysis of hepatic RNA and investigation of immune parameters in plasma were investigated on 5 to 8 sampled individuals per group in order to respect similar sex ratio, sampling time and RNA quality (RNA Integrity Number as determined by Bioanalyser (Agilent) > 9).

\section{Lipid extraction and fatty acid analysis}

One gram of white muscle was dissected from 15 fish per dietary treatment and immediately frozen in liquid nitrogen. Total lipids were extracted according to the method of Folch et al. [31], by Accelerated Solvent Extraction 200 (ASE, Dionex) with dichloromethane/ methanol (2:1) containing $0.01 \%$ butylatedhydroxutoluene $(\mathrm{BHT})$ as antioxidant. Lipids were extracted at 100 bars, $100^{\circ} \mathrm{C}$, with a $5 \mathrm{~min}$ precallingphase, $2 \mathrm{~min}$ static phase, and $60 \%$ flush for $60 \mathrm{sec}$ ( 3 cycles). The separation of neutral and polar lipids was performed according to the procedure described by Juaneda and Roquelin [32]. The total lipid (TL) extracts were fractionated on silica cartridges (Sep-Pack, Waters ${ }^{\circledR}$ ), neutral lipids (NL) were eluted with chloroform and polar lipids (PL) with methanol. Fatty acid methyl esters (FAME) were prepared from total lipids by acid-catalysed transesterification. FAME were quantified by gas-liquid chromatography (Clarus 500, Perkin Elmer) with a BPX70 column of $30 \mathrm{~m}$ length and $0.22 \mathrm{~mm}$ I.D. Hydrogen was used as carrier gas and temperature programming was from $50^{\circ} \mathrm{C}$ to $180^{\circ} \mathrm{C}$ at $20^{\circ} \mathrm{C} / \mathrm{min}$ and then to $220^{\circ} \mathrm{C}$ at $3^{\circ}$ $\mathrm{C} / \mathrm{min}$. Individual methyl esters were identified by comparison with known standards. The fatty acid analysis was performed on one sample per fish.

\section{RNA extraction and real-time quantitative PCR analysis}

Total mRNA of liver was extracted using Trizol reagent (Invitrogen, USA) and quantified by measuring absorbance at $260 \mathrm{~nm}$ in a spectrophotometer (Nanodrop Labtech, France). The reverse transcription was performed using the QuantiTect ${ }^{\circledR}$ Reverse Transcription kit (QIAGEN), including a genomic DNA elimination reaction. Reactions were carried out in a volume of $20 \mu \mathrm{l}$, containing $1 \mu \mathrm{g}$ of total RNA, 1 unit of Quantiscript Reverse Transcriptase, $4 \mu \mathrm{l}$ of Quantiscript RT buffer (5 $x$ ) and $1 \mu \mathrm{M}$ primer mix.

Seven genes involved in metabolic and/or immune pathways of interest (fads2, hmgcr, fabp7, angptl3, cxcl10, gck and $l p l$ ), whose the oligonucleotides were spotted on the chip, were analysed by real-time PCR in order to validate the gene expression patterns obtained through the microarray approach. The relative mRNA levels were automatically normalized with housekeeping elongation factor 1 (ef1) gene expression and measured by Bio-Rad IQ5 software using $\Delta \Delta \mathrm{Ct}$ method ( $\mathrm{Ct}$ for Cycle threshold):

Gene Normalized Expression in sample $1=$ (Gene Relative Quantity in sample 1)/(EF1 Relative Quantity in sample 1) with Relative Quantity in sample 1 for a gene $i=\mathrm{E}_{\text {(gene } i \text { ) }}$ Ct (sample 2) - Ct (sample 1)

Ef1 was chosen to provide an internal control for realtime PCR, since contrary to $18 \mathrm{~S}$ rRNA and actin initially tested, we did not observe any significant difference ( $t$ student test, $\mathrm{p}>0.1$ ) between $\mathrm{Ct}$ values for Ef1 between the dietary groups (See additional file 1: Comparison of $\mathrm{Ct}$ values for ef1 gene between the dietary groups). Its stability was also assessed by a low coefficient of variation over all the samples $(\mathrm{CV}<5 \%)$.

Specific primers (Table 3) were designed from European sea bass sequences of fads 2 (GenBank: EU439924), fabp7 (EMBL: FM000669), hmgcr (EMBL: CB043825), angptl3 (EMBL: FM023639), cxcl10 (EMBL: FM015474), gck (EMBL: AM986860), lpl (EMBL: DT044526) and ef1 (GenBank: AJ866727) (Table 3). All primers used for real-time quantitative PCR analysis were defined with the Primer3 software http://frodo.wi. mit.edu/primer3/ in order to respect an annealing temperature of $60^{\circ} \mathrm{C}$. All PCR reactions were performed with an efficiency of $100 \%( \pm 5 \%)$. The PCR reactions 
Table 3 Primers used for each gene expression analysis by real-time PCR.

\begin{tabular}{|c|c|c|c|}
\hline & Forward primers $\left(5^{\prime}-3^{\prime}\right)$ & Reverse primers $\left(5^{\prime}-3^{\prime}\right)$ & amplicon size \\
\hline FADS2 & CCTTCACTGCTCTTCATCCCAA & CCCAGGTGGAGGCAGAAGAA & 202 \\
\hline FABP7 & GAAGGCACTTGGTGTTGGTT & CAGGGTTITCACCACCACTT & 102 \\
\hline HMGCR & CCAGCTTCGTATTCAGCACA & GCTTGGAGAGGTCGATGAG & 105 \\
\hline LPL & AGTTCCACATCCGGAAACTG & GCTCCGGTTGTCTTCTITTG & 142 \\
\hline GCK & GGTGAAGCAAGCCTGAACTC & CTTCCAGCAGTGACTGTCCA & 122 \\
\hline ANGPTL3 & CAACATCTTGCAGGAGCGTA & CTCTCCGACAGTCCCTTCAG & 77 \\
\hline CXCL10 & GGAGAGTGAGCCAGAACCTG & CCCTTGTGCACTGAAGACAA & 91 \\
\hline EF1 & GCTTCGAGGAAATCACCAAG & CAACCTTCCATCCCTTGAAC & 153 \\
\hline
\end{tabular}

were carried out in an I-cycler with an optical module (Bio-Rad, Hercules, CA, USA), in a final volume of $15 \mu \mathrm{l}$ containing $7.5 \mu$ l SYBR Green Supermix (Biorad, Hercules, CA, USA), $0.5 \mu$ of each primer $(10 \mathrm{mM})$ and 5 $\mu \mathrm{l}$ of cDNA (1/10 dilution). The PCR program consisted of an initial DNA denaturation of $94^{\circ} \mathrm{C}$ for $90 \mathrm{~s}$, followed by 45 cycles at $95^{\circ} \mathrm{C}$ for $30 \mathrm{~s}$ and $60^{\circ} \mathrm{C}$ for $60 \mathrm{~s}$. A triplicate of the amplification reaction was realised for each sample.

\section{Plasma lysozyme concentration}

Plasma lysozyme activity was determined at ambient temperature using a turbidimetric assay [33], adapted to microtitration plates. Briefly, a bacterial suspension of Micrococcus lysodeikticus (Sigma) was prepared at a concentration of $1.25 \mathrm{~g} . \mathrm{l}^{-1}$ in a $0.05 \mathrm{M}$ sodium-phosphate buffer, $\mathrm{pH}$ 6.2. Fifty microlitres of the samples were placed in 96-well microtitration plates. The reaction was initiated in a Labsystems-iEMS analyser, by addition of $160 \mu \mathrm{l}$ well $^{-1} M$. Lysodeikticus suspension using an automatic dispenser. The optic density (OD) reading was taken at a wavelength of $450 \mathrm{~nm}$ every $15 \mathrm{~s}$ for $3 \mathrm{~min}$, the plate being shaken before each reading. Lysozyme values for samples were converted to mg. $\mathrm{ml}^{-1}$, using a reference curve established with hen egg white lysozyme (Sigma).

\section{Plasma alternative complement pathway activity}

Determination of the alternative pathway of plasma complement activity was carried out at $4{ }^{\circ} \mathrm{C}$ through a haemolytic assay with rabbitred blood cells (RRC, Biomérieux, Craponne, France) as described by Yano [34], adapted to microtitration plates. Sea bass samples, diluted to $1 / 64$ in EGTA-Mg-GVB buffer to avoid natural haemolytic activity, were added in increasing amounts, from 10 to $100 \mu \mathrm{l} \mathrm{well}^{-1}$. Wells were filled with EGTA-Mg-GVB buffer to a final volume of $100 \mu \mathrm{l}$. Finally, $50 \mu \mathrm{l}$ of $2 \%$ RRC (Biomérieux) suspension was added to each of the wells. Control values of $0 \%$ and $100 \%$ haemolysis were obtained using $100 \mu \mathrm{l}$ of EGTAMg-GVB buffer and $100 \mu \mathrm{l}$ of non-decomplemented trout haemolytic serum at 1/50 in ultrapure water, respectively. The samples were then incubated for $1 \mathrm{~h}$ at $20^{\circ} \mathrm{C}$. The microplates were centrifuged $(400 \mathrm{~g}, 5 \mathrm{~min}$, $4^{\circ} \mathrm{C}$ ) and $75 \mu \mathrm{l}$ of supernatant from each well was then transferred into another 96-well microplate with $75 \mu \mathrm{l}$ of phosphate buffered saline (PBS, Biomérieux). The absorbance $\left(A_{540}\right)$ was read in a Labsystems-iEMS analyser and the number of $\mathrm{ACH}_{50}$ units per ml of plasma was determined by reference to the $50 \%$ haemolysis.

\section{Dicentrarchus labrax oligonucleotide microarray}

Gene expression profiles were investigated using the Agilent-019810 Dicentrarchus labrax oligo microarray (GEO accession: GPL9663). This platform represents 19, 035 unique transcripts of the European sea bass. Two non-overlapping probes were designed for each transcript for a total 38, 070 oligonucleotide probes $(60$ mers) synthesized onto the array (for details see [35]). All sequences (DLPD) are publicly available in a dedicated database [35], together with associated annotations, GO entries and putative homologous genes in fish model species.

Microarrays were synthesized in situ using Agilent non-contact ink-jet technology with a $4 \times 44 \mathrm{~K}$ format, and included default positive and negative controls. Microarray analysis was based on a single color (Cy3) design. A mixture of 10 different viral polyadenilated RNAs (Agilent Spike-In Mix) was also added to each RNA sample to monitor labelling and hybridization quality as well as microarray analysis work-flow.

Sample labelling and hybridization were performed as reported in Ferraresso et al. [28]. Briefly, for each sample, $200 \mathrm{ng}$ of total RNA were linearly amplified and labelled with Cy3-dCTP according to the Agilent OneColor Microarray-Based Gene Expression Analysis protocol. A mixture of 10 different viral polyadenilated RNAs (Agilent Spike-In Mix) was also added to each RNA sample to monitor labelling and hybridization quality as well as microarray analysis work-flow. After fragmentation, a total of 1, $650 \mathrm{ng}$ of labelled cRNA were dispensed in the gasket slide and assembled to the microarray slide (each slide containing four arrays). Slides were incubated for $17 \mathrm{~h}$ at $65^{\circ} \mathrm{C}$ in an Agilent 
Hybridization Oven and washed following manufacturer's instructions.

\section{Data acquisition and normalization}

Hybridized slides were scanned at $5 \mu \mathrm{m}$ resolution using an Agilent G2565BA DNA microarray scanner. Default settings were modified to scan the same slide twice at two different sensitivity levels (XDR Hi 100\% and XDR Lo $10 \%)$. The two linked images generated were analyzed together; data were extracted and background subtracted using the standard procedures contained in the Agilent Feature Extraction (FE) Software version 9.5.1. Spike-in probe intensities were used to assess the performance of the normalization procedure for each dataset. Data normalization was performed using $R$ statistical software http://www.r-project.org; microarray data were normalized across all arrays using the cyclic loess approach [36]. Fold changes (FC) were calculated for each gene by finding the average value for each group (dietary or sibfamily group). Raw and normalized fluorescence data of the present microarray experiment have been deposited in the GEO database under accession number (under submission: NCBI tracking system \#16023742).

\section{Statistical analysis}

All the results are presented as mean values with standard deviations (SD). Daily Growth Coefficient (DGC) was studied using a model accounting for diet as a fixed effect and tank, sire, dam, sire*diet and dam*diet as random effects, using SAS-GLM. Effects of diet and halfsibfamily factors on biometry (hepatosomatic index: HSI and viscerosomatic index: VSI), fatty acid composition, gene expression (qPCR), plasma lysozyme concentration and alternative complement pathway activity were tested by two-way ANOVAs $(P<0.05)$ using Statistica biosoft 8.0. The microarray data were analysed by two-way ANOVA using Tmev (Tigr MultiExperiment Viewer) statistical software, and gene expression was considered significantly different when $P<0.01$. Significant enrichment of GO biological process categories were tested for using EASE software (version 2.0) with $P<0.05$ [35].

\section{Results}

\section{Growth and biometry}

After 9 months of the feeding trial, European sea bass fed VD exhibited significantly lower DGC than those FD (Table 4). In addition, the fish of half-sibfamily $G$ fed the VD had a significantly higher DGC than fish of halfsibfamily $g$ fed VD, while there was no difference between these two half-sibfamilies when they were both fed FD (Table 4). The hepatosomatic index (HSI) was regulated by diet and genetic factors while the viscerosomatic index (VSI) was only regulated by the genetic factor. There were no significant interactions between dietary and genetic factors for these two parameters. The feed efficiency (FE) in the duplicate tanks was 0.56 and 0.60 for the FD and 0.51 and 0.55 for the VD, respectively. Mortality was not significantly different between dietary treatment and half-sibfamilies (Table 4).

\section{Lipid and fatty acid compositions of the fillet}

The flesh lipid composition was significantly affected by dietary treatment (See additional file 2: Fatty acid composition in muscle). Feeding VD significantly increased the percentage of saturated lipids in both the neutral lipids and phospholipids. The $\alpha$-linolenic acid (18:3n-3) and linoleic acid (18:2n-6) contents were respectively 10-fold and 3-fold higher, in both lipid classes, when fish were fed VD. In addition, AA, EPA and DHA

Table 4 Growth and biometric parameters of two half-sibfamilies of European sea bass ( $G$ and $g$ ) fed fish-based and plant-based diets.

\begin{tabular}{|c|c|c|c|c|c|c|c|}
\hline & \multicolumn{2}{|c|}{ FD } & \multicolumn{2}{|c|}{ VD } & \multirow[b]{2}{*}{ Diet factor } & \multirow[b]{2}{*}{ Sib family factor } & \multirow[b]{2}{*}{ Diet $\times$ Sib family factors } \\
\hline & HSF $\mathrm{g}$ & HSF G & HSF $\mathrm{g}$ & HSF G & & & \\
\hline & & & & & $p$ value & $p$ value & $p$ value \\
\hline Initial length (cm) & $22.5 \pm 1.8$ & $21.7 \pm 2.5$ & $21.2 \pm 1.7$ & $21.9 \pm 1.5$ & NS & NS & NS \\
\hline Initial weight (g) & $218 \pm 55$ & $178 \pm 61$ & $179 \pm 45$ & $178 \pm 36$ & 0.01 & NS & 0.01 \\
\hline Final length (cm) & $31.1 \pm 2.1$ & $30.3 \pm 2.7$ & $28.9 \pm 1.8$ & $30.0 \pm 1.9$ & 0.01 & NS & NS \\
\hline Final weight (g) & $625 \pm 138$ & $553 \pm 154$ & $475 \pm 97$ & $513 \pm 96$ & 0.01 & NS & 0.01 \\
\hline HSI (\%) & $2.67 \pm 0.1$ & $2.07 \pm 0.1$ & $2.09 \pm 0.1$ & $1.90 \pm 0.1$ & 0.01 & 0.01 & NS \\
\hline VSI (\%) & $6.86 \pm 0.24$ & $5.44 \pm 0.35$ & $7.17 \pm 0.22$ & $6.39 \pm 0.34$ & NS & 0.01 & NS \\
\hline$D G C^{(10-4)}$ & $103.5 \pm 5.7$ & $103.9 \pm 11.1$ & $92.2 \pm 3.4$ & $98.0 \pm 6.7$ & 0.01 & NS & 0.01 \\
\hline FE & \multicolumn{2}{|c|}{$0.56-0.60$} & \multicolumn{2}{|c|}{$0.51-0.55$} & - & - & - \\
\hline Survival (\%) & 99.5 & 99.5 & 100 & 100 & NS & NS & NS \\
\hline
\end{tabular}

Initial and final weights and lengths $(n=15), \mathrm{HSI}(\mathrm{n}=75)$ and VSI $(\mathrm{n}=75)$. Effects of diet factor and genetic factor on the biometric parameters are determined by two-way ANOVA. Results are expressed as mean +/- S.D. and significant differences are indicated by the $p$ value (two-way ANOVA, $P<0.05$ ). 
contents were around 2.5-fold lower in flesh of fish fed VD. The $\Sigma$ n-3 PUFA $/ \Sigma$ n- 6 PUFA ratio decreased in both the neutral lipid (2-fold) and phospholipid (4-fold) fractions in the flesh of European sea bass fed VD.

\section{Microarray gene expression profiling}

A list of 4, 272 significant probes was obtained for the effect of diet factor, corresponding to 582 unique transcripts with gene ontology (GO) annotation. Among these regulated transcripts, 358 exhibited higher levels in fish fed VD while 224 were over-expressed in the liver of fish fed FD. For the family factor effect, total of 989 significant probes were revealed corresponding to 199 unique transcripts with GO annotation. Among these, 116 exhibited higher levels in half-sibfamily $G$ while 83 were more abundant in half-sibfamily $g$. In addition, 297 probes related to 72 genes with functional annotation exhibited significant diet $\times$ genetic interactions. The main biological processes enriched out of those associated with genes that were over-expressed in fish fed VD were physiological process (324 genes), metabolism (267 genes), RNA splicing (16 genes), protein catabolism (34 genes), aerobic respiration (5 genes), sterol metabolism (8 genes), carboxylic metabolism (30 genes), amino acid metabolism (18 genes), blood coagulation (12 genes) and hexose catabolism (8 genes) (See additional file 3: Significantly enriched biological processes associated with genes regulated by diet and halfsibfamily factors). The genes involved in carboxylic acid and sterol metabolism included fatty acid desaturase 2, steroyl-CoA desaturase 9, NADH-cytochrome b5 reductase, Isopentenyl-diphosphate delta-isomerase 1, Lanosterol 14-alpha demethylase, Farnesyl pyrophosphate synthase, C-4 methylsterol oxidase and 3-hydroxy-3methylglutaryl-coenzyme A reductase. Apolipoprotein A-I, Apolipoprotein B-100 and lipoprotein lipase, implicated in lipid transport, were also found to be upexpressed in fish fed VD (Table 5). Similarly, some genes involved in carbohydrate metabolism (hexose catabolism), such as glucose-6-phosphate 1-dehydrogenase, 6-phosphogluconate dehydrogenase and fructose-1, 6bisphosphatase 1 were also expressed at a higher level in the fish fed VD (Table 5). Expression levels of genes involved in protein metabolism and amino acid metabolism were also increased in fish fed VD (Table 5).

In contrast, the main biological processes enriched associated with the genes that were lower-expressed in fish fed VD were particularly related to cellular process (136 genes), cell communication (65 genes) and cell proliferation (32 genes) (See additional file 3: Significantly enriched biological processes associated with genes regulated by diet and half-sibfamily factors). In addition, some genes involved in the immune function were less expressed in fish fed VD (Table 5).
The comparison of hepatic transcriptomes between the two half-sibfamilies indicated that genes involved in immune function, such as complement component $\mathrm{C} 2$, $\mathrm{C} 3$ and C9 and mannan-binding lectin serine protease 2, were more greatly expressed in half-sibfamily $g$ than in half-sibfamily $G$ (Table 6). Inversely, expression levels of NADH dehydrogenase genes (ndufb4, ndufb6, ndufs 4 , $n d u f s 6$ and $n d u s v 2$ ), involved in the electron transport to the respiratory chain, were significantly lower in halfsibfamily $g$ compared with half-sibfamily $G$. Half-sibfamily $g$ was also characterised by lower expression level of genes implicated in ATP production (atp5c1 and atp5g3) and protein synthesis, such as ribosomal subunits (mrpl22, mrpl27, mrpl30, mrpl34, mrpl48, mrps14 and mrps 17 ) than the half-sibfamily $G$ (Table 6). Among the 72 genes exhibiting an interaction between half-sibfamily and diet factors, 50 were involved in metabolism. However, only the processes related to aromatic amino acid family ( $h p d, h p g d$ and $h s d 17 b 4$ ) and nucleotide metabolism (ctps, dck, gmpr, nt5e and $t \ln 1$ ) were found to be over-represented among these genes (Table 7).

In order to validate the accuracy of the microarray data, the fads2, hmgcr, fabp7, angptl3, cxcl10, gck and $l p l$ genes, which were spotted on the microarray, were also investigated by means of real-time PCR. The comparison of the gene expression pattern obtained through the real-time PCR and microarray approaches, revealed a correlation greater than 0.75 (Table 8).

\section{Immune parameters}

Lysozyme activity was significantly lower $(0.7$-fold; $P<$ 0.05 ) in fish fed VD than in fish fed FD, while the alternative complement activity was 1.5 -times higher $(P<$ $0.05)$ (Figure 1). There was no effect of the half-sibfamily factor on these activities.

\section{Discussion}

The present work is the first investigation into the effect of an exclusively vegetable diet on the hepatic transcriptome in a marine fish species. It is also the first study to have explored the transcriptome of two half-sibfamilies of European sea bass exhibiting different capacities to grow on such a diet. The replacement of FM and FO with increasing levels of plant protein and oil sources for marine fish species can modify feed intake and conversion, which should be the major reason for associated growth delay $[37,38]$. In the present study, there was a tendency for higher FE in fish fed FD $(0.56,0.60)$ compared with fish fed VD $(0.51,0.55)$. However, this difference could not be statistically tested since fish were reared in only two tanks per diet condition. A vegetable diet is also known to potentially impact fish metabolism through regulation of gene expression, especially in the liver $[8,39,40]$. Analysis of the oligo-DNA microarray 
Table 5 Genes involved in the main physiological processes regulated by dietary treatments.

\begin{tabular}{|c|c|c|c|}
\hline Physiological process & Swiss prot description & Gene name & Fold-change (FC) \\
\hline \multirow[t]{16}{*}{ Lipid metabolism and transport } & Fatty acid desaturase 2 & FADS2 & 4.9 \\
\hline & Stearoyl-CoA 9-desaturase & SCD9 & 1.4 \\
\hline & NADH-cytochrome b5 reductase 2 & CYB5R2 & 2.0 \\
\hline & 1-acyl-sn-glycerol-3-phosphate acyltransferase gamma & AGPAT3 & 2.3 \\
\hline & Phosphatidylserine decarboxylase proenzyme & PISD & 2.8 \\
\hline & Phosphatidylinositol-glycan biosynthesis class F protein & PIGF & 1.6 \\
\hline & Isopentenyl-diphosphate Delta-isomerase 1 & IDI1 & 2.0 \\
\hline & Lanosterol 14-alpha demethylase & CYP51A1 & 3.6 \\
\hline & Farnesyl pyrophosphate synthase & FDPS & 2.6 \\
\hline & C-4 methylsterol oxidase & SC4MOL & 2.6 \\
\hline & 3-hydroxy-3-methylglutaryl-coenzyme A reductase & HMGCR & 4.4 \\
\hline & Apolipoprotein A-I & APOA1 & 1.3 \\
\hline & Apolipoprotein B-100 & APOB100 & 1.5 \\
\hline & Lipoprotein lipase & $L P L$ & 3.1 \\
\hline & Angiopoietin-related protein 3 & ANGPTL3 & 0.3 \\
\hline & Phosphatidylcholine-sterol acyltransferase & LCAT & 1.9 \\
\hline \multirow[t]{6}{*}{ Carbohydrate metabolism } & Glucose-6-phosphate 1-dehydrogenase & G6PDH & 1.3 \\
\hline & Hexose-6-phosphate 1-dehydrogenase & $\mathrm{H} 6 \mathrm{PDH}$ & 1.2 \\
\hline & 6-phosphogluconate dehydrogenase & PGD & 1.5 \\
\hline & Fructose-1, 6-bisphosphatase 1 & FBP1 & 2.3 \\
\hline & Fructose-bisphosphate aldolase A & ALDOA & 2.7 \\
\hline & Fructose-bisphosphate aldolase B & ALDOB & 2.3 \\
\hline \multirow[t]{8}{*}{ Protein metabolism } & Proteasome subunit alpha type- 4 & PSMA & 1.2 \\
\hline & Proteasome subunit beta type-7 & PSMB7 & 1.3 \\
\hline & $26 S$ protease regulatory subunit 7 & PSMC2 & 1.3 \\
\hline & $26 S$ proteasome non-ATPase regulatory subunit 4 & PSMD4 & 1.5 \\
\hline & Ubiquitin-associated protein 1 & UBAP1 & 1.8 \\
\hline & Ubiquitin-conjugating enzyme E2 A & UBE2A & 1.9 \\
\hline & Ubiquitin-conjugating enzyme E2 G1 & UBE2G1 & 1.7 \\
\hline & Ubiquitin-conjugating enzyme E2 N & UBE2N & 1.2 \\
\hline \multirow[t]{8}{*}{ Amino acid metabolism } & CTP synthase 1 & CTPS & 1.7 \\
\hline & Glutamine amidotransferase & GMPS & 1.8 \\
\hline & Alpha-aminoadipate aminotransferase & AADAT & 1.7 \\
\hline & Glutamate oxaloacetate transaminase 1 & GOT1 & 4.4 \\
\hline & Tyrosine aminotransferase & TAT & 2.6 \\
\hline & Succinate dehydrogenase iron-sulfur subunit & SDHB & 1.4 \\
\hline & Isocitrate dehydrogenase subunit gamma & $\mathrm{IDH} 3 g$ & 1.3 \\
\hline & Malate dehydrogenase & $\mathrm{MDH}$ & 2.5 \\
\hline \multirow[t]{10}{*}{ Immune function } & Interleukin-8 & IL8 & 0.5 \\
\hline & C-X-C motif chemokine 10 & CXCL10 & 0.5 \\
\hline & C-reactive protein & CRP & 0.5 \\
\hline & Lysozyme g like protein & LYG & 0.7 \\
\hline & Integrin beta-2 & ITGB2 & 0.6 \\
\hline & Receptor-type tyrosine-protein phosphatase F & PTPRF & 0.5 \\
\hline & Prostaglandin synthase 2 & PTGS2 & 0.6 \\
\hline & Fatty acid-binding protein & FABP7 & 4.5 \\
\hline & Plasma protease $\mathrm{C} 1$ inhibitor & SERPING1 & 1.3 \\
\hline & Prostaglandin D2 synthase 2 & PTGS3 & 0.6 \\
\hline \multirow[t]{3}{*}{ Cell communication } & Cytokine receptor common subunit gamma & IL2RG & 0.5 \\
\hline & protein tyrosine phosphatase, receptor type, F & PTPRF & 0.5 \\
\hline & Integrin beta-2 & ITGB2 & 0.6 \\
\hline
\end{tabular}


Table 5 Genes involved in the main physiological processes regulated by dietary treatments. (Continued)

\begin{tabular}{|c|c|c|c|}
\hline \multirow[t]{10}{*}{ Blood coagulation } & Antithrombin-III & SERPINC1 & 1.9 \\
\hline & Plasma protease $\mathrm{C} 1$ inhibitor & SERPING1 & 1.3 \\
\hline & Vitamin K-dependent protein S & PROS1 & 1.4 \\
\hline & Plasminogen & PLG & 1.4 \\
\hline & Platelet glycoprotein 4 & CD36 & 2.2 \\
\hline & Coagulation factor $X$ & F10 & 1.3 \\
\hline & Prothrombin & F2 & 1.2 \\
\hline & Coagulation factor VII & F7 & 1.5 \\
\hline & Fibrinogen beta chain & $F G B$ & 1.3 \\
\hline & Fibrinogen gamma chain & FGG & 1.3 \\
\hline
\end{tabular}

The fold-changes $(\mathrm{FC})$ are indicated considering FD as the reference group. (two-way ANOVA, $P<0.01$ ).

data by two-way ANOVA indicated that several hundred genes were differentially regulated according to diet or/ and half-sibfamily factors. The accuracy of the present microarray data is validated by the similar gene pattern expression obtained from different oligonucleotides representing the same genes spotted on the array (data not shown), as well as by the correlation shown between results of microarray and qPCR approaches.

\section{LC-PUFA metabolism}

Metabolism-related biological processes constitute the largest group among the GO terms associated with the

Table 6 Genes involved in the main physiological processes regulated by the genetic factor.

\begin{tabular}{|c|c|c|c|}
\hline Physiological process & Swiss prot description & Gene name & Fold-change (FC) \\
\hline \multirow[t]{5}{*}{ Immune function } & Complement C2 & $\mathrm{C} 2$ & 1.2 \\
\hline & Complement C3 & C3 & 1.7 \\
\hline & Complement component C9 & C9 & 1.5 \\
\hline & Mannan-binding lectin serine protease 2 & MASP2 & 1.3 \\
\hline & Tumor necrosis factor receptor superfamily member 14 & TNFRS14 & 1.7 \\
\hline \multirow[t]{6}{*}{ Electron transport for ATP synthesis } & NADH dehydrogenase [ubiquinone] 1 beta subcomplex subunit 4 & NDUFB4 & 0.8 \\
\hline & NADH dehydrogenase [ubiquinone] 1 beta subcomplex subunit 6 & NDUFB6 & 0.8 \\
\hline & NADH dehydrogenase [ubiquinone] iron-sulfur protein 4 & NDUFS4 & 0.8 \\
\hline & NADH dehydrogenase [ubiquinone] iron-sulfur protein 6 & NDUFS6 & 0.7 \\
\hline & $\mathrm{NADH}$ dehydrogenase [ubiquinone] flavoprotein 2 & NDUFV2 & 0.8 \\
\hline & Cytochrome b-c1 complex subunit 7 & UQCRB & 0.8 \\
\hline \multirow[t]{6}{*}{ Energy pathway } & ATP synthase subunit gamma & ATP5C1 & 0.4 \\
\hline & ATP synthase lipid-binding protein & ATP5G3 & 0.5 \\
\hline & Cytochrome c oxidase copper chaperone & $\operatorname{cox} 17$ & 0.8 \\
\hline & Cytochrome b-245 heavy chain & Cybb & 0.6 \\
\hline & 3-hydroxyisobutyrate dehydrogenase & HIBADH & 0.7 \\
\hline & Mitochondrial inner membrane protein & OXA1L & 0.8 \\
\hline \multirow[t]{13}{*}{ Protein biosynthesis } & T-complex protein 1 subunit beta & $\mathrm{CCT} 2$ & 0.8 \\
\hline & Eukaryotic translation initiation factor 4 gamma 1 & EIF4G1 & 0.6 \\
\hline & Basic helix-loop-helix domain-containing protein KIAA2018 & KIAA2018 & 0.9 \\
\hline & 395 ribosomal protein $L 22$ & MRPL22 & 0.8 \\
\hline & $39 S$ ribosomal protein L27 & MRPL27 & 0.8 \\
\hline & 395 ribosomal protein L30 & MRPL30 & 0.8 \\
\hline & 395 ribosomal protein L34 & MRPL34 & 0.7 \\
\hline & 395 ribosomal protein $L 48$ & MRPL48 & 0.7 \\
\hline & $28 \mathrm{~S}$ ribosomal protein $\mathrm{S14}$ & MRPS14 & 0.8 \\
\hline & $28 \mathrm{~S}$ ribosomal protein S17 & MRPS17 & 0.8 \\
\hline & 605 ribosomal protein L18 & RPL18 & 0.7 \\
\hline & 605 acidic ribosomal protein P1 & RPLP1 & 0.8 \\
\hline & $40 S$ ribosomal protein S18 & RPS18 & 0.8 \\
\hline
\end{tabular}

The fold-changes (FC) are indicated considering the half-sibfamily $g$ as the reference group. (two-way ANOVA, $P<0.01$ ). 
Table 7 Genes involved in the main physiological processes regulated by genetic and diet factors interactions.

\begin{tabular}{lll}
\hline Physiological process & Swiss prot description & Gene name \\
\hline Aromatic amino acid family & 4-hydroxyphenylpyruvate dioxygenase & HPD \\
& 15-hydroxyprostaglandin dehydrogenase & HPGD \\
Nucleotide metabolism & Peroxisomal multifunctional enzyme type 2 & HSD17B4 \\
& CTP synthase 1 & CTPS \\
& Deoxycytidine kinase & GMPR \\
GMP reductase 1 & NT5E \\
5'-nucleotidase & TLN1 \\
\hline
\end{tabular}

genes regulated in VD-fed fish. Among these, genes involved in lipid metabolism and, particularly, in LCPUFA biosynthesis, were found to be up-regulated in fish fed VD. Not surprisingly, delta-6-desaturase ( $f a d s 2)$, steroyl-CoA desaturase $9(s c d 9)$ and NADH-cytochrome b5 reductase (cyb5r2), involved in long chain fatty acid desaturation and/or elongation, were up-regulated in VD-fed fish. It is indeed established that in most fish species that the LC-PUFA biosynthetic pathway is positively regulated in response to the use of a diet poor in LC-PUFA but rich in PUFA, although this regulation depends on fish species, degree of fish oil substitution, nature of the vegetable oil, and environmental parameters (e.g., salinity) [41].

The positive regulation of the LC-PUFA biosynthetic pathway is in agreement with results obtained by transcriptomic approaches in salmonids fed vegetable oil $[39,40]$. Altogether, the expression data obtained in marine fish species and salmonids indicate that the different capacity of marine and fresh water species to grow on a LC-PUFA-deprived diet does not seem to be due to a different transcriptional regulation of key genes involved in lipid synthesis, such as $f a d s 2$ or $s c d 9$. Indeed, the level of induction of $f a d s 2$ expression found in this experiment (5-fold induction) is of similar amplitude to that observed in the liver and intestine of Atlantic salmon [42].

The stimulation of this biosynthetic pathway in fish fed a diet poor in LC-PUFAs can be explained by the fact that LC-PUFAs play several key physiological roles in vertebrates, particularly in fish. For example, fish are poikilothermic organisms and therefore need a high degree of unsaturation of LC-PUFA included in membrane phospholipids to maintain phospholipid bilayer fluidity at reduced temperature [43]. LC-PUFA, especially arachidonic acid (ARA) and eicosapentaenoic acid (EPA), are also precursors of eicosanoids, which are involved in pro and anti-inflammatory pathways. This hypothesis is reinforced by our data, indicating a stimulation of genes involved in phospholipids biosynthesis (agpat3, pisd and pigf) when fish were fed the VD.

Despite this stimulation of LC-PUFA and the phospholipid biosynthesis pathway at the transcriptional level, our investigation of fatty acid profiles indicated that the amounts of LC-PUFA, particularly eicosapentaenoic acid (EPA) and docosahexaenoic acid (DHA), were still considerably lower in the flesh of fish from both half-sibfamilies fed VD in comparison with fish fed FD. This finding is in agreement with those previously obtained [13], which revealed that the stimulation of fads 2 expression in fish fed a vegetable diet was not associated with an induction of its enzymatic activity, suggesting a post-transcriptional regulation of fads 2 expression. Such EPA and DHA deficiency can notably explain the growth deficiency observed in fish fed VD, as well as effects observed on immune function (discussed below).

Concerning the genetic aspect, the comparable overall expression pattern of genes involved in LC-PUFA synthesis in the liver, associated with similar LC-PUFA profile in muscle, in both half-sibfamilies suggests that the differing capacities of these European sea bass half-

Table 8 Correlation between gene expression patterns obtained through real-time PCR and microarray approaches.

\begin{tabular}{lll}
\hline Gene name & Swiss-prot description & Correlation coefficient \\
\hline angpt/3 & Angiopoietin-related protein 3 & 0.75 \\
cxcl10 & C-X-C motif chemokine 10 & 0.77 \\
fabp7 & Fatty acid-binding protein & 0.86 \\
gck & Glycerol kinase & 0.90 \\
hmgcr & 3-hydroxy-3-methylglutaryl-coenzyme A reductase & 0.96 \\
lpl & Lipoprotein lipase & 0.85 \\
fads2 & Fatty acid desaturase 2 & 0.89 \\
\hline
\end{tabular}



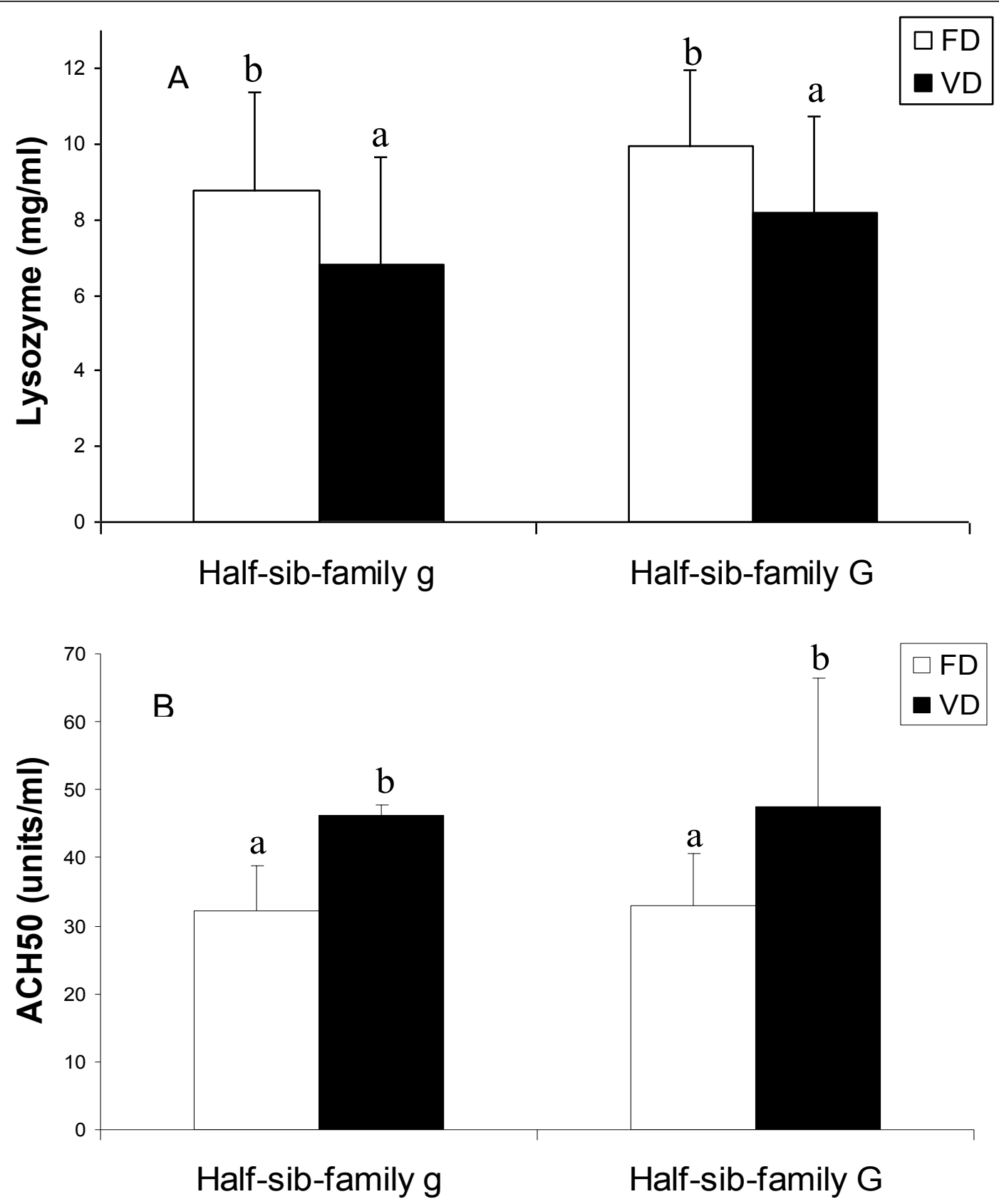

Figure 1 Influence of the vegetable diet on plasma lysozyme concentration (A) and alternative complement pathway activity (B). Results are expressed as mean +/- S.D. $(n=15)$. Different letters indicate significant differences (two-way ANOVA, $P<0.05$ ).

sibfamilies to grow on a vegetable diet are not due to differing capacities to synthesize LC-PUFA.

\section{Sterol metabolism}

The present microarray data also indicate an increase in expression levels of genes involved in sterol metabolism in VD-fed fish. Among these, isopentenyl-diphosphate delta-isomerase 1 (idi1), lanosterol 14-alpha demethylase (cyp51a1), farnesyl pyrophosphate synthase (fdps), c-4 methylsterol oxidase (sc4mol) and 3-hydroxy-3-methylglutaryl-coenzyme A reductase ( $h m g \mathrm{cr}$ ) genes [44-49] are known to be implicated in the cholesterol metabolic pathway (Figure 2). More particularly, HMGCR, a transmembrane glycoprotein involved in the rate-limiting step of sterol biosynthesis, is increased, as shown in mammals [50]. The stimulation of cholesterol biosynthesis in fish fed VD could be related to the difference in sterol composition between diets. Indeed, while the fish 


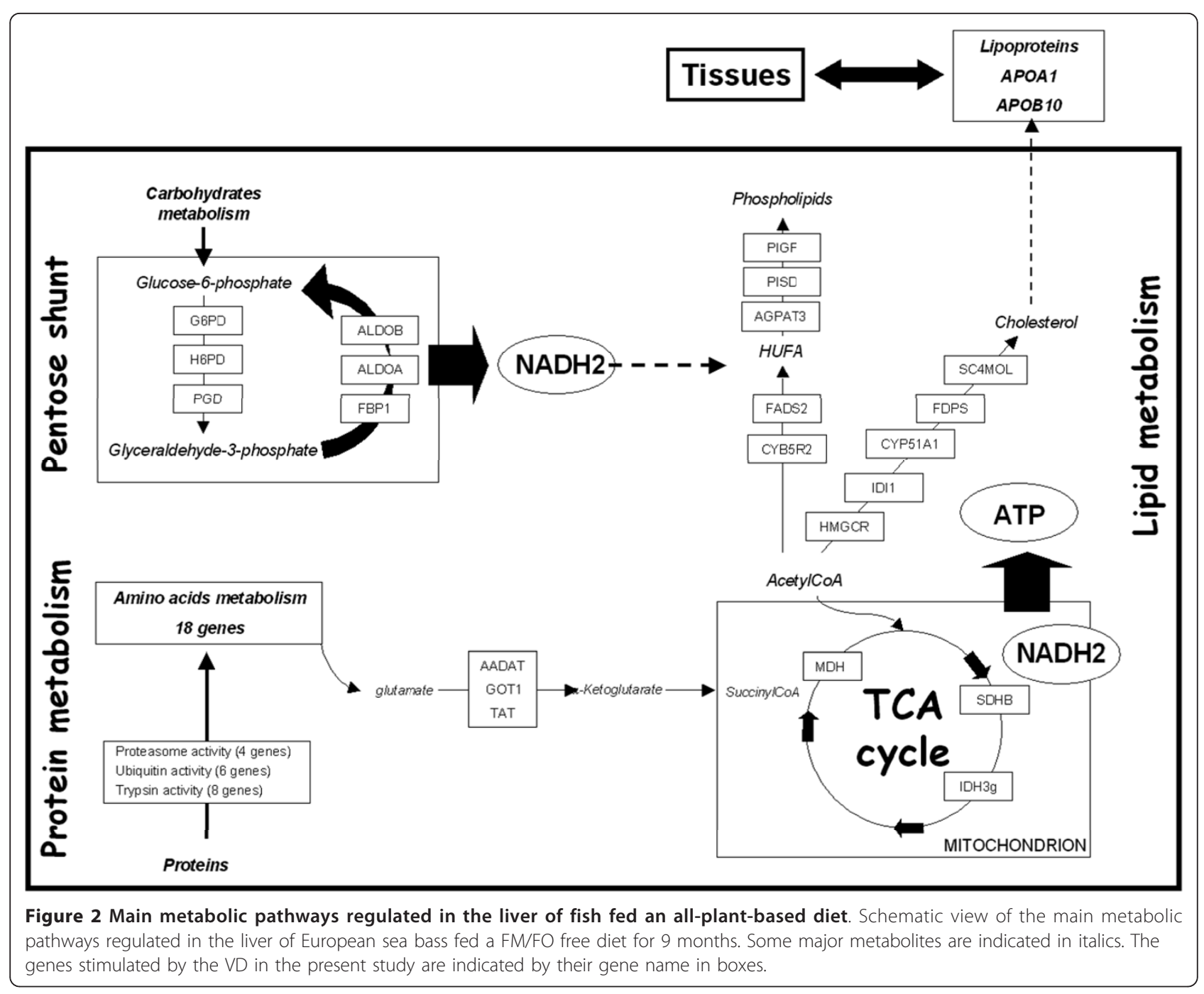

diet is rich in cholesterol, the vegetable diet used in this experiment contains exclusively plant sterols, which have been shown to affect membrane properties by decreasing permeability and fluidity, and modifying phospholipid order in mammals [51,52]. As a consequence, the increase in cholesterol biosynthesis could be a metabolic response to its deficiency in the diet, as well as a way to restore membrane properties by incorporation of endogenous cholesterol. Since we did not measure the cholesterol content in the liver, flesh or blood, it is not possible for us to assess the capacity of European sea bass to compensate for possible dietary deficiencies in cholesterol through a regulation of its biosynthesis. Moreover, similarly to the LC-PUFA pathway, no significant difference of cholesterol biosynthetic regulation was observed between the half-sibfamilies.

Interestingly, several VD-stimulated genes ( $f a d s 2$, hmgcr, idi1, cyp51a1, fdps and sc4mol) involved in the lipogenic pathway (LC-PUFA and sterol pathways) are known to be molecular targets of sterol regulatory element binding proteins (SREBPs), which are key regulators of fatty acid and cholesterol synthesis $[53,54]$. Recent data indicating an up-regulation of the srebp-1 gene expression in European sea bass fed a vegetable diet [13] could thus be due to such stimulations.

\section{Lipid and sterol transport}

The present microarray data indicate that the stimulation of genes involved in fatty acid and cholesterol synthesis in VD-fed fish was associated with an overexpression of genes involved in their transport, such as apolipoproteins APOA1 and APOB100, which are the major protein constituents of high and low density lipoprotein (HDL, LDL), respectively (Figure 2 ). The LDL, including APOB100, are involved in the transport of cholesterol and lipids from the liver to other tissues. Thus, up-regulation of apob100 combined with the induction of the expression of lipoprotein lipase $(l p l)$, a 
key enzyme involved in the hydrolysis of triglyceride, suggests an increase in lipid transport and metabolism from the liver to tissues in fish fed VD. The decrease in angiopoietin-related protein 3 (angptl3) that we observed in fish fed VD reinforces this idea since ANGPTL3 suppresses LDL clearance via the inhibition of LPL activity [55]. In parallel, we observed that the reverse transport of cholesterol not used by tissues via HDL to the liver was also stimulated in fish fed VD. Indeed, APOA1, which participates in the transport of cholesterol to the liver by promoting cholesterol efflux from tissues and by acting as a cofactor for the lecithin cholesterol acyltransferase (lcat), exhibited higher transcript levels in fish fed VD. Altogether these results reveal that another major response in the liver of European sea bass fed a vegetable diet is the stimulation of cholesterol synthesis and transport, irrespective of the half-sibfamily considered.

\section{Carbohydrate metabolism}

LC-PUFA and cholesterol biosynthesis require reducing power in the form of NADPH. It is well documented in vertebrates, including fish, that NADPH required for malonyl-CoA synthesis is mainly supplied by the dehydrogenases of the pentose phosphate shunt $[39,56,57]$. Interestingly, our transcriptomic data indicate that the use of the VD induced a significant increase in the level of glucose-6-phosphate dehydrogenase ( $g 6 p d$ transcripts). G6PD catalyses NADP+-linked oxidation of Dglucose-6-phosphate and has been shown to be a major contributor of NADPH production for lipogenesis in Atlantic salmon (Salmo salar) [58] and European sea bass [58]. Moreover, our data indicate an increase in the expression of hexose-6-phosphate dehydrogenase $(h 6 p d h)$ and phosphogluconate dehydrogenase $(p g d)$, enzymes of the pentose phosphate pathway that generate NADPH, in fish fed VD [59,60] (Figure 2). Once synthesized, the resulting pentose sugar intermediate generated by the pentose phosphate pathway can be reconverted to intermediates of the glycolysis/gluconeogenesis pathway such as glyceraldehyde $3 \mathrm{P}$ or fructose $6 \mathrm{P}$. In the liver of fish, it is known that glycolysis provides essential precursors for biosynthesis rather than pyruvate for oxidation [61]. Thus, the stimulation of fructose-1, 6-bisphosphatase $1(f b p 1)$ and aldolase (aldoa and aldob) expression that we observe in fish fed VD could provide high levels of fructose-6-phosphate from glyceraldehyde $3 \mathrm{P}$, then glucose $6 \mathrm{P}$ that serves as substrate for repeated passage in the pentose phosphate shunt (Figure 2).

\section{Protein/amino-acid metabolism and ATP synthesis}

Our data revealed over-expression of genes involved in proteolysis and, more particularly, in proteasome activity (psma4, psmb7, psmc2 and psmd4) and ubiquitin activity (ubap1, ube2a, ube2g1 and ube2n) in fish fed VD (Figure 2), which is in total agreement with proteomic data obtained in rainbow trout, indicating a stimulation of proteolysis in fish fed vegetable diets [8]. In our study, the stimulation of proteolysis in the fish fed the vegetable diet was associated with the induction of 18 genes involved in amino acid metabolism and, more importantly, 4 genes involved in glutamine metabolism. In addition, gmps, aadat, got 1 and tat genes, which are implicated in transamination, were also stimulated in fish fed VD. The processes related to amino acid metabolism and, especially transamination, are important steps in the synthesis of some non-essential amino acids such as $\alpha$-ketoglutarate. For example, the synthesis of $\alpha$-ketoglutarate through transamination reactions could be used in the TCA cycle to provide energy. Interestingly, we found over-expression of genes encoding enzymes involved in the TCA cycle, such as succinate dehydrogenase $(s d h b)$, isocitrate dehydrogenase $(i d h 3 g)$ and malate dehydrogenase $(m d h)$, in fish fed VD. This stimulation of the TCA cycle could be related to the higher levels of ATP required for LC-PUFA and cholesterol biosynthesis in fish fed VD. Since marine fish have a low capacity to digest complex carbohydrates, in contrast to mammals $[62,63]$, the use of proteins as an essential source of energy can thus explain the stimulation of the amino acid metabolism in fish fed VD. As shown in rainbow trout fed on a vegetable-based diet [64], the lower growth rate in fish fed VD in the present study could be associated with higher proteolytic activity compared with fish fed FD.

Interestingly, while both half-sibfamilies $G$ and $g$ exhibited similar proteolysis regulation, the expression of several genes involved in macromolecule biosynthesis, and particularly in protein biosynthesis (cct2, eif4g1, kiaa2018, mrpl22, mrpl27, mrpl30, mrpl34, mrpl48, mrps14, mrps17, rars, rpl18, rplp1 and rps18), were upregulated in half-sibfamily $G$. This result, suggesting a higher protein turnover in half-sibfamily $G$ compared with half-sibfamily $g$ when fish were fed VD, could be related to the higher growth rate observed in half-sibfamily $G$ fed VD. As protein biosynthesis requires energy from ATP hydrolysis, the higher protein biosynthesis in half-sibfamily could be related to a higher activity of mitochondrial ATP production. Accordingly, genes involved in ATP biosynthesis (atp 5c1, atp $5 i$ and atp5j2) and ATP synthesis-coupled electron transport (ndufb4, ndufb6, ndufs4, ndufs6, ndufv2 and uqcrb) were found up-regulated in half-sibfamily $G$. The diet $\times$ halfsibfamily interaction that we found for the expression of genes involved in aromatic amino acid metabolism reinforces the difference in protein metabolism between the two half-sibfamilies. 


\section{Immune function}

In the present study, the vegetable diet used, based on linseed oil, was characterised by a very low ARA content and poor levels of n-3 LC-PUFA. Eicosanoids derived from ARA are known to be involved in the proliferation of hepatocytes and immune cells [65-67]. As a consequence, the lower hepatosomatic index (HSI) measured in fish fed VD could be linked to a lower hepatocyte proliferation due to a deficiency in ARA, which was supported by down-expression of 32 genes involved in cell proliferation in this dietary group. Moreover, fatty acid imbalances can induce an immune deficiency in all vertebrates including fish $[14,15,22]$. In particular, the $\Sigma$ n$3 / \Sigma n-6$ fatty acid ratio is considered as a key element regulating immune cell structure, cell signalling, and eicosanoid production.

The present microarray data revealed genes of the immune system, particularly the innate immune response, exhibiting lower expression in fish fed with VD. Interleukin 8 (ils) and C-X-C motif chemokine 10 (cxcl10), which are chemotactic factors for granulocytes and monocytes, respectively, were found to be less expressed in fish fed VD, suggesting a down regulation of the innate defence system and the pro-inflammatory pathway in this group. Deficiency of the inflammatory response was also in agreement with the higher levels of transcripts of fatty acid binding protein 7 ( $f a b p 7$ ), whose expression in mammals has been shown to be restricted to the Kupffer cells [68], and the down expression of the $\mathrm{C}$-reactive protein ( $c r p)$, an acute phase protein synthesised by hepatocytes, in fish fed VD. Decrease in inflammatory response can also be related to the low level of ARA in the fish fed VD, which induces a reduction of prostaglandin synthesis derived from this fatty acid. Our microarray data indeed show that prostaglandin E synthase 2 (ptgs 2 ), involved in the synthesis of pro-inflammatory prostaglandin E2, is down-regulated in fish fed VD, while prostaglandin E synthase 3 (ptgs3), which has anti-inflammatory properties, exhibited higher messenger levels in fish fed VD. This depression of innate immune system, particularly pro-inflammatory activity, could also be partially explained by a defect in membrane properties in fish fed VD, as revealed by the down-regulation of a large number of genes (65) related to cell communication, including factors such as cytokine receptor common subunit gamma (il2rg), receptortype tyrosine-protein phosphatase $\mathrm{F}$ (ptprf) or integrin beta 2 (itgb2), which are cell-surface receptor binding proteins and/or cell adhesion receptors involved in immune response. The depression of the innate immune response in fish fed VD was confirmed by the lower plasmatic lysozyme concentration and lower-expression of lysozyme g (lyg) gene. Surprisingly, the alternative complement pathway activity involved in the innate immune response, which we assessed by analysis of plasma parameters, showed a significantly higher level in fish fed VD. Such an opposite regulation of the immune pathway revealed that different components of the immune systems can be regulated in opposite directions.

Interestingly, processes related to the humoral immune response were also over-represented among the genes up-regulated in half-sibfamily $g$. Indeed, complement component $c 2, c 3$ and $c 9$ genes showed higher expression levels in half-sibfamily $g$. However, the upregulation of genes involved in the alternative complement pathway cannot be associated with an increase of the plasma alternative complement pathway activity, probably due to the complexity of factors and regulation levels (transcriptional and post-transcriptional) involved in the regulation of this pathway [69]. Moreover, the higher expression of masp2, tnrfrf14, c2 and $c 3$ genes involved in the inflammatory response might reflect higher inflammatory states in half-sibfamily $g$, which could be associated with a decrease in growth rate, as demonstrated in chicken [70].

\section{Blood coagulation}

Blood coagulation is another process involved in the innate immune system. LC-PUFA and, more specifically, EPA, DHA and ARA are precursors for eicosanoid synthesis involved in the control of the blood coagulation [71-73]. As mentioned above, the use of a diet composed of vegetable protein and oil induces modifications in the membrane phospholipid composition, with possible consequences for eicosanoid production and the blood coagulation process. We found that the use of the vegetable diet induced an increase in the expression of genes involved in the blood coagulation pathway (Figure 3). Among these genes, prothrombin (f7), coagulation factor $\times(f 10)$, fibrinogen beta chain $(f g b)$, fibrinogen gamma chain $(f g g)$ and coagulation factor VII $(f 7)$ were positively involved in the blood coagulation process. On the basis of these results, the use of a VD seems to cause pro-coagulant action by the stimulation of the blood coagulation pathway, which is in agreement with our visual observation of plasma clotting (data not shown). In agreement with these results, Tavares-Dias [23] showed that, contrary to a vegetable diet, dietary enrichment in long-chain n-3 fatty acids has a strong hypocoagulant action. In addition, the regulation of the coagulation pathway is complex and under the control of several negative factors that maintain a physiological homeostasis. The pro-coagulation effect in response to a vegetable diet is notably reinforced by some of these genes [the vitamin K-dependent protein $\mathrm{S}$ (pros1), plasminogen ( $p l g)$ and antithrombinIII (serpinc1)], which also exhibited higher expression in fish fed VD (Figure 3). 


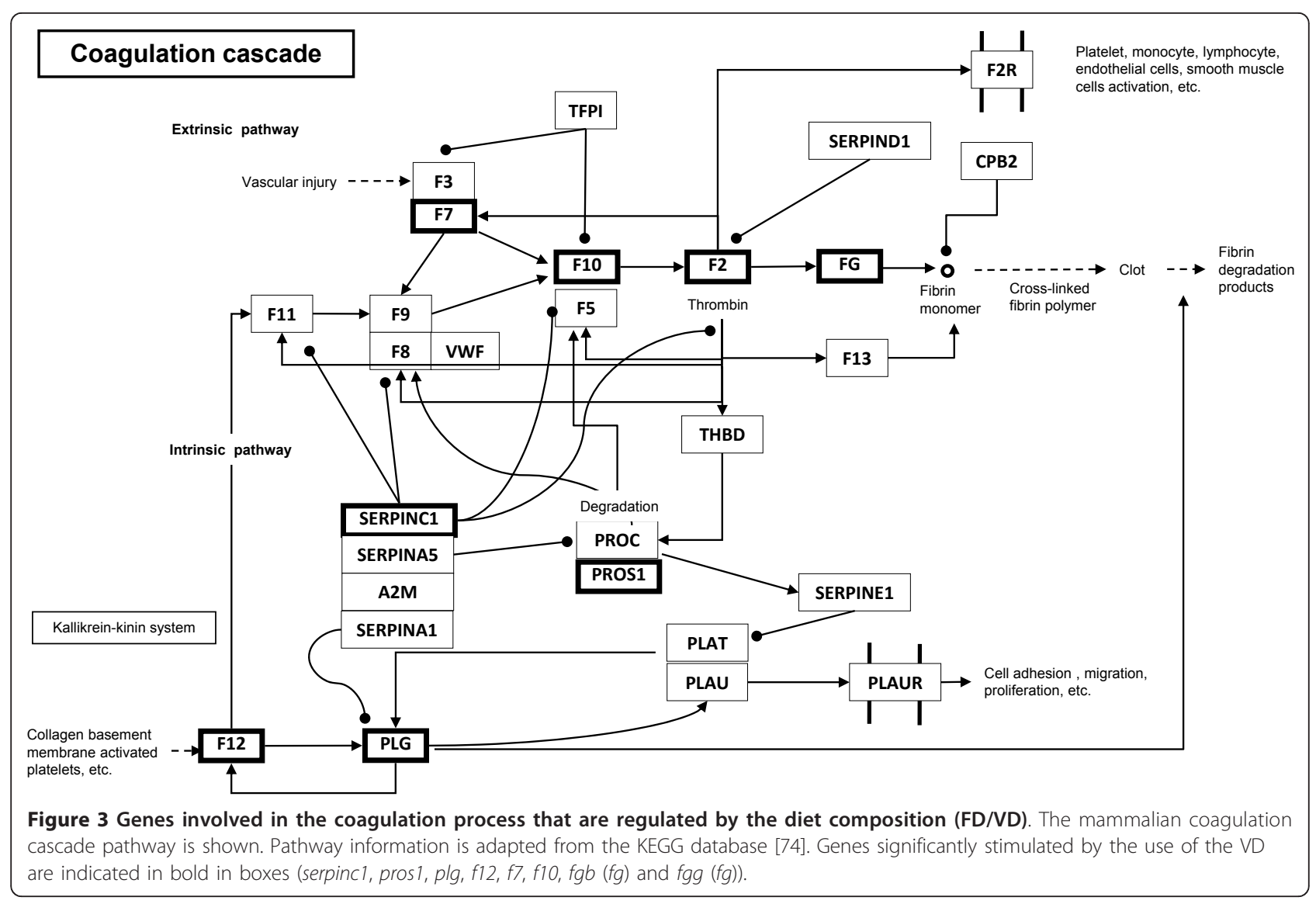

\section{Conclusions}

The nutrigenomic approach used here has revealed several new genes and related biological processes regulated by a vegetable diet. In particular, genes involved in lipid metabolism, protein/amino acid metabolism, carbohydrate metabolism, immune function, blood coagulation and the RNA splicing process were expressed at a higher level in fish fed with VD. The comparison of transcriptomic response in two half-sibfamilies of fish exhibiting different growth rates when fed the vegetable diet also revealed some biological processes related to protein turnover and immune response, potentially due to better adaptation to this diet. Finally, in the context of developing novel diets for aquaculture and selecting fish families exhibiting higher adaptation to fish oil and meal substitution, this work enabled us to pinpoint potentially useful new molecular markers for identifying the physiological effects of a vegetable diet, as well as a family exhibiting a phenotype of interest.

\section{Additional material}

Additional file 1: Comparison of $\mathrm{Ct}$ values for ef 1 gene between the dietary groups. Quantitative PCR did not reveal any significant

difference (t-student test, $p>0$. 1) between $C t$ values for Ef1 between the dietary groups (FD: Fish diet; VD: Vegetable diet; G: G-sibfamily; g: gsibfamily).

Additional file 2: Fatty acid composition in muscle of two European sea bass half-sibfamilies fed FD or VD. Composition in terms of the main fatty acids (\% of total fatty acids) in neutral lipid and phospholipid fractions in muscle of each of the half-sibfamilies ( $g$ and $G$ ) of European sea bass fed FD or VD. Effects of diet factor and half-sibfamily factor on fatty acid composition were determined by two-way ANOVA. Results are expressed as mean +/- S.D. $(n=15)$ and significant differences are indicated by the $p$ value (two-way ANOVA, $P<0.05$ ).

Additional file 3: Significantly enriched biological processes associated with genes regulated by diet and half-sibfamily factors (EASE, $P<0.05$ ). The main biological processes enriched out of those associated with genes that were over-expressed in fish fed VD were related to physiological process, metabolism (sterol metabolism, carboxylic metabolism, amino acid metabolism), RNA splicing, protein catabolism, aerobic respiration, blood coagulation and hexose catabolism. In contrast, the main biological processes associated with the genes lower-expressed in fish fed VD were related to cellular process, cell communication and cell proliferation. Regarding half-sibfamily factors, biological process related to Humoral immune response was shown to be over-represented within genes up-expressed in half-sibfamily $g$ while processes related to energy pathways (ATP synthesis, mitochondrial electron transport) were enriched within genes up-expressed in halfsibfamily $G$.

List of abbreviations

ALA: a-linolenic acid; ARA: arachidonic acid; DGC: daily growth coefficient; DHA: docosahexaenoic acid; DM: dry matter; EF1: elongation factor 1; EPA: 
eicosapentaenoic acid; FD: fish diet; FE: feed efficiency; GO: gene ontology; HDL: high density lipoprotein; HSI: hepatosomaticindex; LA: linoleic acid; LCPUFA: long chain polyunsaturated fatty acid; LDL: low density lipoprotein; NL: neutral lipid; PL: polar lipid; PUFA: polyunsaturated fatty acid; TL: total lipid; VD: vegetable diet; VSI: viscerosomatic index.

\section{Acknowledgements}

This work was supported by Marine Genomics Europe, Europôle Mer Axis 1: "Genomics and 'Blue Chemistry' ". The authors thank H. Le Delliou for fatty acid analysis, F. Ruelle for European sea bass breeding, F. Terrier for making the experimental diets, F. Lamour, C. Huelvan, E. Desbruyères for the measurement of immune parameters on plasma, Dr. A. Henaut for discussion on microarrays analysis and H. McCombie for English revisions.

\section{Author details}

'Ifremer, UMR 1067, Departement Physiologie Fonctionnelle des Organismes Marins, Technopôle Brest-Iroise, BP 70, 29280 Plouzané, France. ²Department of Public Health, Comparative Pathology, and Veterinary Hygiene, Faculty of Veterinary Medicine, University of Padova, Vialedell'Università 16, 35020 Legnaro, Italy. ${ }^{3}$ Anses, Laboratoire de Ploufragan/Plouzané, Agence nationale de sécurité sanitaire de l'aliment, de l'environnement et du travail, Technopôle Brest-Iroise, 29280 Plouzané, France. ${ }^{4}$ Ifremer, chemin de Maguelone, 34250 Palavas les Flots, France. ${ }^{5}$ INRA, UMR 1313 Génétique Animale et Biologie Intégrative, Domaine de Vilvert, 78350 Jouy-en-Josas, France. ${ }^{6}$ INRA-UMR Nutrition Aquaculture Génomique, Pôle Hydrobiologie, 64310 Saint Pée-sur-Nivelle, France.

\section{Authors' contributions}

FG and DM co-ordinated the sampling procedures, biochemical studies and microarray data analysis, and drafted the manuscript. SF and LB carried out the sample preparation, hybridizations and microarray data normalizations. SK formulated the experimental diet. MV participated in the design of the study and performed analysis of growth parameters. CC and JLZ conceived and designed the study and led its coordination. CQ co-ordinated dedicated experiments on immune function. All authors read and approved the final manuscript.

Received: 2 March 2011 Accepted: 23 October 2011

Published: 23 October 2011

\section{References}

1. Barlow S: Fishmeal and oil: sustainable feed ingredients for aquafeeds. Global Aquaculture Advocate 2000, 4:85-88.

2. Kaushik S: Use of alternative protein sources for the intensive rearing of carnivorous fishes. In Mediterranean Aquaculture. Edited by: Flos R, Tort L, Torres P. UK: Ellis Horwood; 1990:125-138.

3. Tacon AGJ, Metian M: Global overview on the use of fish meal and fish oil in industrially compounded aquafeeds: Trends and future prospects. Aquaculture 2008, 285(1-4):146-158.

4. Bell JG, Waagbø R: Safe and nutritious aquaculture produce: benefits and risks of alternative sustainable aquafeeds. In Aquaculture in the ecosystem. Edited by: Holmer M, Black KD, Duarte CM, Marba N, Karakassis I. Netherlands: Springer Verlag; 2008:185-225.

5. Benedito-Palos L, Navarro JC, Sitja-Bobadilla A, Bell JG, Kaushik S, PerezSanchez J: High levels of vegetable oils in plant protein-rich diets fed to gilthead sea bream (Sparus aurata L.): growth performance, muscle fatty acid profiles and histological alterations of target tissues. Br J Nutr 2008, 100(5):992-1003.

6. Torstensen BE, Espe M, Sanden M, Stubhaug I, Waagbo R, Hemre Gl, Fontanillas R, Nordgarden U, Hevroy EM, Olsvik P, et al: Novel production of Atlantic salmon (Salmo salar) protein based on combined replacement of fish meal and fish oil with plant meal and vegetable oil blends. Aquaculture 2008, 285(1-4):193-200.

7. Panserat S, Ducasse-Cabanot S, Plagnes-Juan E, Srivastava PP, Kolditz C, Piumi F, Esquerre D, Kaushik S: Dietary fat level modifies the expression of hepatic genes in juvenile rainbow trout (Oncorhynchus mykiss) as revealed by microarray analysis. Aquaculture 2008, 275(1-4):235-241.

8. Vilhelmsson OT, Martin SAM, Medale F, Kaushik SJ, Houlihan DF: Dietary plant-protein substitution affects hepatic metabolism in rainbow trout (Oncorhynchus mykiss). Br J Nutr 2004, 92(1):71-80.
9. Kaushik SJ, Coves D, Dutto G, Blanc D: Almost total replacement of fish meal by plant protein sources in the diet of a marine teleost, the European seabass, Dicentrarchus labrax. Aquaculture 2004, 230(14):391-404.

10. Bell MV, Dick JR, Porter AEA: Pyloric ceca are amajor site of 22:6n-3 synthesis in rainbow trout (Oncorhynchus mykiss). Lipids 2003, 39:39-44.

11. Richard N, Kaushik S, Larroquet L, Panserat S, Corraze G: Replacing dietary fish oil by vegetable oils has little effect on lipogenesis, lipid transport and tissue lipid uptake in rainbow trout (Oncorhynchus mykiss). Br J Nutr 2006, 96(2):299-309.

12. Sargent JR, Tacon AG: Development of farmed fish: a nutrionnally necessary alternative to meat. proceedings of the Nutrition Society 1999 58:377-383.

13. Geay F, Santigosa I, Culi E, Corporeau C, Boudry P, Dreano Y, Corcos L, Bodin N, Vandeputte M, Zambonino-Infante $J$, Mazurais D, et al: Regulation of FADS2 expression and activity in European sea bass (Dicentrarchus labrax, L.) fed a vegetable diet. Comp Biochem Physiol B 2010, 156:237-243.

14. Montero D, Grasso V, Izquierdo MS, Ganga R, Real F, Tort L, Caballero MJ, Acosta F: Total substitution of fish oil by vegetable oils in gilthead sea bream (Sparus aurata) diets: Effects on hepatic Mx expression and some immune parameters. Fish \& Shellfish Immunology 2008, 24(2):147-155.

15. Montero D, Mathlouthi F, Tort L, Afonso JM, Torrecillas S, FernandezVaquero A, Negrin D, Izquierdo MS: Replacement of dietary fish oil by vegetable oils affects humoral immunity and expression of proinflammatory cytokines genes in gilthead sea bream Sparus aurata. Fish \& Shellfish Immunology 2010, 29(6):1073-1081.

16. Benedito-Palos L, Saera-Vila A, Calduch-Giner JA, Kaushik S, Perez-Sanchez J: Combined replacement of fish meal and oil in practical diets for fast growing juveniles of gilthead sea bream (Sparus aurata L.): Networking of systemic and local components of GH/IGF axis. Aquaculture 2007, 267(1-4):199-212.

17. Ghioni C, Tocher DR, Bell MV, Dick JR, Sargent JR: Low C-18 to C-20 fatty acid elongase activity and limited conversion of stearidonic acid, 18: 4 $(n-3)$, to eicosapentaenoic acid, 20: $5(n-3)$, in a cell line from the turbot, Scophthalmus maximus. Biochimica Et Biophysica Acta-Molecular and Cell Biology of Lipids 1999, 1437(2):170-181.

18. Owen JM, Adron JW, Middleton C, Cowey CB: Elongation and desaturation of dietary fatty acids in turbot Scophthalmus maximus L., and rainbow trout, salmo gairdnerii rich. Lipids 1975, 10(9):528-531.

19. Tocher DR, Ghioni C: Fatty acid metabolism in marine fish: Low activity of fatty acyl Delta 5 desaturation in gilthead sea bream (Sparus aurata) cells. Lipids 1999, 34(5):433-440.

20. Bell JG, Tocher DR, Farndale BM, Cox DI, McKinney RW, Sargent JR: The effect of dietary lipid on polyunsaturated fatty acid metabolism in Atlantic salmon (Salmo salar) undergoing Parr-Smolt transformation. Lipids 1997, 32(5):515-525.

21. Bell JG, Tocher DR, Macdonald FM, Sargent JR: Effects of diets rich in linoleic $(18: 2 n-6)$ and alpha-linolenic $(18: 3 n-3)$ acids on the growth, lipid class and fatty-acid compositions and eicosanoid production in juvenile turbot (Scophthalmus maximus L.). Fish Physiol Biochem 1994, 13(2):105-118

22. Montero D, Kalinowski T, Obach A, Robaina L, Tort L, Caballero MJ, Izquierdo MS: Vegetable lipid sources for gilthead seabream (Sparus aurata): effects on fish health. Aquaculture 2003, 225(1-4):353-370.

23. Tavares-Dias M, Oliveira SR: A review of the blood coagulation system of fish. Revista Brasileira de Biociências 2009, 7(2):205-224.

24. Dupont-Nivet M, Medale F, Leonard J, Le Guillou S, Tiquet F, Quillet E, Geurden I: Evidence of genotype-diet interactions in the response of rainbow trout (Oncorhynchus mykiss) clones to a diet with or without fishmeal at early growth. Aquaculture 2009, 295(1-2):15-21.

25. Palti Y, Silverstein JT, Wieman H, Phillips JG, Barrows FT, Parsons JE: Evaluation of family growth response to fishmeal and gluten-based diets in rainbow trout (Oncorhynchus mykiss). Aquaculture 2006, 255(14):548-556.

26. Pierce LR, Palti Y, Silverstein JT, Barrows FT, Hallerman EM, Parsons JE: Family growth response to fishmeal and plant-based diets shows genotype $\times$ diet interaction in rainbow trout (Oncorhynchus mykiss). Aquaculture 2008, 278(1-4):37-42.

27. Le Boucher R, Vandeputte M, Dupont-Nivet M, Quillet E, Mazurais D, Robin J, Vergnet A, Médale F, Kaushik S, Chatain B: A first insight into 
genotype $\times$ diet interactions in European sea bass (Dicentrarchus labrax L. 1756) in the context of plant-based diet use. Aquaculture Research 2010, 1-10.

28. Ferraresso S, Vitulo N, Mininni AN, Romualdi C, Cardazzo B, Negrisolo E, Reinhardt R, Canario AVM, Patarnello T, Bargelloni L: Development and validation of a gene expression oligo microarray for the gilthead sea bream (Sparus aurata). Bmc Genomics 2008, 9.

29. Cho C: Feeding systems for rainbow trout and other salmonids with reference to current estimates of energy and protein requirements. Aquaculture 1992, 100(1-3):107-123.

30. Carter C, Houlihan D, Kiessling A, Medale F, Jobling M: Food intake in fish. Oxford: Blackwell Science; 2001.

31. Folch J, Lees M, Sloane-Stanley GH: A simple method for the isolation and purification of total lipids from animal tissues. J Biol Chem 1957, 226:497-509.

32. Juaneda P, Rocquelin G: Rapid and convenient separartion of phospholipids and non phosphorus lipids from rat heart using silica cartridges. Lipids 1985, 20(1):40-41.

33. Grinde B, Lie O, Poppe T, Salte R: Species and individual variation in lysozyme activity in fish of interest in aquaculture. Aquaculture 1988, 68(4):299-304

34. Yano T: Assays of haemolytic complement activity. In Techniques in Fish Immunology. Volume 2. Edited by: Stolen JS, Fletcher TC, Anderson DP, Kaattari SL, Rowley AF. USA; 1992.

35. Ferraresso S, Milan M, Pellizzari C, Vitulo N, Reinhardt R, Canario AVM, Patarnello T, Bargelloni L: Development of an oligo DNA microarray for the European sea bass and its application to expression profiling of jaw deformity. Bmc Genomics 2010, 11.

36. Barbacioru CC, Wang YL, Canales RD, Sun YMA, Keys DN, Chan F, Poulter KA, Samaha RR: Effect of various normalization methods on Applied Biosystems expression array system data. Bmc Bioinformatics 2006, 7.

37. Carter CG, Hauler RC: Fish meal remplacement by plant meals in extruded feeds for Atlantic salmon, Salmo salar L. Aquaculture 2000, 185:299-311.

38. de Francesco M, Parisi G, Medale F, Lupi P, Kaushik SJ, Poli BM: Effect of long-term feeding with a plant protein mixture based diet on growth and body/fillet quality traits of large rainbow trout (Oncorhynchus mykiss). Aquaculture 2004, 236(1-4):413-429.

39. Leaver MJ, Villeneuve LAN, Obach A, Jensen L, Bron JE, Tocher DR, Taggart JB: Functional genomics reveals increases in cholesterol biosynthetic genes and highly unsaturated fatty acid biosynthesis after dietary substitution of fish oil with vegetable oils in Atlantic salmon (Salmo salar). Bmc Genomics 2008, 9.

40. Panserat S, Kolditz C, Richard N, Plagnes-Juan E, Piumi F, Esquerre D, Medale F, Corraze G, Kaushik S: Hepatic gene expression profiles in juvenile rainbow trout (Oncorhynchus mykiss) fed fishmeal or fish oil-free diets. Br J Nutr 2008, 100(5):953-967.

41. Leaver MJ, Bautista JM, Bjornsson BT, Jonsson E, Krey G, Tocher DR, Torstensen BE: Towards Fish Lipid Nutrigenomics: Current State and Prospects for Fin-Fish Aquaculture. Reviews in Fisheries Science 2008, 16:73-94.

42. Zheng $X$, Tocher DR, Dickson CA, Bell JG, Teale AJ: Highly unsaturated fatty acid synthesis in vertebrates: new insights with the cloning and characterization of a $\Delta 6$ desaturase of Atlantic salmon. Lipids 2005, 40:13-24.

43. Palmerini CA, Mazzoni M, Giovinazzo G, Arienti G: Blood lipids in Antarctic and in Temperate-Water Fish Species. Journal Membrane Biology 2009, 230:125-131.

44. Bennati AM, Castelli M, Caruso D, Beccari T, Della Fazia MA, Servillo G, Roberti R: Sterol dependent regulation of human TM7SF2 gene expression supports a role of the encoded 3 beta-hydroxysterol Delta (14) reductase in cholesterol biosynthesis. Chemistry and Physics of Lipids 2005, 136(2):118-119.

45. Drzewinska J, Pulaski L, Soszynski M, Bartosz G: Seladin-1/DHCR24: A key protein of cell homeostasis and cholesterol biosynthesis. Postepy Higieny I Medycyny Doswiadczalnej 2009, 63:318-330.

46. Juvan P, Rezen T, Rozman D, Monostory K, Pascussi J, Belic A: Towards Identification of Gene Interaction Networks of Human Cholesterol Biosynthesis. Acta Chimica Slovenica 2008, 55:396-407.
47. Nwokoro NA, Wassif CA, Porter FD: Genetic disorders of cholesterol biosynthesis in mice and humans. Molecular Genetics and Metabolism 2001, 74(1-2):105-119.

48. Pandit J, Danley DE, Schulte GK, Mazzalupo S, Pauly TA, Hayward CM, Hamanaka ES, Thompson JF, Harwood HJ: Crystal structure of human squalene synthase - A key enzyme in cholesterol biosynthesis. J Biol Chem 2000, 275(39):30610-30617.

49. Welch CL, Xia YR, Shechter I, Farese R, Mehrabian M, Mehdizadeh S, Warden CH, Lusis AJ: Genetic regulation of cholesterol homeostasis: Chromosomal organization of candidate genes. Journal of Lipid Research 1996, 37(7):1406-1421.

50. Fink M, Spaninger K, Prosenc U, Rozman D: High-fat medium and circadian transcription factors (Cryptochrome and Clock) contribute to the regulation of cholesterogenic Cyp51 and Hmgcr genes in mouse embryonic fibroblasts. Acta Chimica Slovenica 2008, 55(1):85-92.

51. Mora MP, Tourne-Peteilh C, Charveron M, Fabre B, Milon A, Muller I: Optimisation of plant sterols incorporation in human keratinocyte plasma membrane and modulation of membrane fluidity. Chemistry and Physics of Lipids 1999, 101(2):255-265.

52. Ratnayake WMN, L'Abbe MR, Mueller R, Hayward S, Plouffe L, Hollywood R, Trick K: Vegetable oils high in phytosterols make erythrocytes less deformable and shorten the life span of stroke-prone spontaneously hypertensive rats. J Nutr 2000, 130(5):1166-1178.

53. Dentin R, Girard J, Postic C: Carbohydrate responsive element binding protein (ChREBP) and sterol regulatory element binding protein- $1 \mathrm{c}$ (SREBP-1c): two key regulators of glucose metabolism and lipid synthesis in liver. Biochimie 2005, 87(1):81-86.

54. Horton JD, Shah NA, Warrington JA, Anderson NN, Park SW, Brown MS, Goldstein JL: Combined analysis of oligonucleotide microarray data from transgenic and knockout mice identifies direct SREBP target genes. $P$ Natl Acad Sci USA 2003, 100(21):12027-12032.

55. Kersten S: Regulation of lipid metabolism via angiopoietin-like proteins. Biochem Soc Trans 2005, 33:1059-1062.

56. Boujard T, Gelineau A, Coves D, Corraze G, Dutto G, Gasset E, Kaushik S: Regulation of feed intake, growth, nutrient and energy utilisation in European sea bass (Dicentrarchus labrax) fed high fat diets. Aquaculture 2004, 231(1-4):529-545

57. Regost C, Arzel J, Robin J, Rosenlund G, Kaushik SJ: Total replacement of fish oil by soybean or linseed oil with a return to fish oil in turbot (Psetta maxima) - 1. Growth performance, flesh fatty acid profile, and lipid metabolism. Aquaculture 2003, 217(1-4):465-482.

58. Dias J, Huelvan C, Dinis MT, Metailler R: Influence of dietary bulk agents (silica, cellulose and a natural zeolite) on protein digestibility, growth, feed intake and feed transit time in European seabass (Dicentrarchus labrax) juveniles. Aquatic Living Resources 1998, 11(4):219-226.

59. Hewitt KN, Walker EA, Stewart PM: Minireview: Hexose-6-phosphate dehydrogenase and redox control of 11 beta-hydroxysteroid dehydrogenase type 1 activity. Endocrinology 2005, 146(6):2539-2543.

60. Senesi S, Csala M, Marcolongo P, Fulceri R, Mandl J, Banhegyi G, Benedetti A: Hexose-6-phosphate dehydrogenase in the endoplasmic reticulum. Biological Chemistry 2010, 391(1):1-8.

61. Guillaume J, Kaushik S, Bergot P, Métailler R: Nutrition et alimentation des poissons et crustacés. France: INRA, IFREMER; 1999.

62. Cowey $\mathrm{CB}, \mathrm{Cho} \mathrm{CY}$ : Nutritional requirements of fish. Proceedings of the Nutrition Society 1993, 52(3):417-426.

63. Kaushik SJ, Medale F: Energy-requirements, utilization and dietary supply to salmonids. Aquaculture 1994, 124(1-4):81-97.

64. Dobly A, Martin SAM, Blaney SC, Houlihan DF: Protein growth rate in rainbow trout (Oncorhynchus mykiss) is negatively correlated to liver $20 \mathrm{~S}$ proteasome activity. Comparative Biochemistry and Physiology a-Molecular \& Integrative Physiology 2004, 137(1):75-85

65. Adachi T, Nakashima S, Saji S, Nakamura T, Nozawa Y: Roles of prostaglandin production and mitogen-activated protein-kinase activation in hepatocyte growth factor-mediated rat hepatocyte proliferation. Hepatology 1995, 21(6):1668-1674.

66. Calder PC: Immunomodulation by omega-3 fatty acids. Prostaglandins Leukotrienes and Essential Fatty Acids 2007, 77(5-6):327-335.

67. Skouteris GG, Ord MG, Stocken LA: Regulation of the proliferation of primary rat hepatocytes by eicosanoids. Journal of Cellular Physiology 1988, 135(3):516-520 
68. Abdelwahab SA, Owada Y, Kitanaka N, Iwasa H, Sakagami H, Kondo H: Localization of brain-type fatty acid-binding protein in Kupffer cells of mice and its transient decrease in response to lipopolysaccharide. Histochemistry and Cell Biology 2003, 119(6):469-475.

69. Bjorge L: The complement system - Structure, activation, regulation and functions. Tidsskrift for den Norske Laegeforening 1999, 119(2):226-233.

70. Korver DR, Klasing KC: Dietary fish oil alters specific and inflammatory immune responses in chicks. J Nutr 1997, 127(10):2039-2046.

71. Petrukhina GN, Kalugin SA, Makarov VA: The effect of N-3 polyunsaturated fatty acids on the blood coagulation system. Eksperimental'naya i Klinicheskaya Farmakologiya 1997, 60(1):76-88.

72. Salbach $P B$, Specht $E$, Vonhodenberg E, Kossmann J, Janssentimmen $U$, Schneider WJ, Hugger P, King WC, Glomset JA, Habenicht AJR: Differential low-density-lipoprotein receptor-dependent formation of eicosanoids in human blood-derived monocytes. P Natl Acad Sci USA 1992, 89(6):2439-2443.

73. Smith HR, Larsen GL, Cherniack RM, Wenzel SE, Voelkel NF, Westcott JY, Bethel RA: Inflammatory cells and eicosanoids mediators in subjects with late asthmatic responses and increases in airway responsiveness. Journal of Allergy and Clinical Immunology 1992, 89(6):1076-1084.

74. Kanehisa M, Goto S, Hattori M, Aoki-Kinoshita KF, Itoh M, Kawashima S, Katayama T, Araki M, Hirakawa M: From genomics to chemical genomics: new developments in KEGG. Nucleic Acids Research 2006, 34:D354-D357.

75. NRC: In Nutrient Requirements of Fish. Edited by: Sciences NAo. Washington, DC, USA; 1993:114.

doi:10.1186/1471-2164-12-522

Cite this article as: Geay et al.: Effects of the total replacement of fishbased diet with plant-based diet on the hepatic transcriptome of two European sea bass (Dicentrarchus labrax) half-sibfamilies showing different growth rates with the plant-based diet. BMC Genomics 2011 12:522.

\section{Submit your next manuscript to BioMed Central and take full advantage of:}

- Convenient online submission

- Thorough peer review

- No space constraints or color figure charges

- Immediate publication on acceptance

- Inclusion in PubMed, CAS, Scopus and Google Scholar

- Research which is freely available for redistribution

Submit your manuscript at www.biomedcentral.com/submit 